\title{
PENGARUH VARIASI TEMPERATUR PERLAKUAN PANAS AGING TERHADAP SIFAT MEKANIK ALUMINIUM AA 6061
}

\author{
Jaelani Sidik $^{1 *}$, M. Sholihin ${ }^{2}$, Riyan Arthur ${ }^{3}$
}

\begin{abstract}
ABSTRAK
Aluminum 6061 is widely used in industry such as automotive industry, household appliances and construction. With its use in various fields with different characteristics, surely a method is needed to increase the value of its strength. This study aims to increase the mechanical strength value of aluminum 6061. Aging heat treatment is a method that can increase the value of mechanical strength. The aging temperature variations in this study are 175, 200 and 225 with holding time of one hour and cooled in the open air. Then the test consists of hardness test, tensile test and impact test. The results show that aging process can affects of the mechanical properties of aluminum. Maximum hardness value, maximum tensile strength and highest impact value are reached at an aging temperature of $175^{\circ} \mathrm{C}$ with values of $31.66 \mathrm{HRB}, 231.67 \mathrm{Mpa}$ and $0.0290 \mathrm{Kg} . \mathrm{m} / \mathrm{mm}$, respectively. But the increasing temperature of aging, the value of hardness, tensile strength values trend to decrease. The decrease in mechanical properties of aluminum 6061 is due to the condition of over aging at temperatures of $200^{\circ} \mathrm{C}$ and $225^{\circ} \mathrm{C}$.
\end{abstract}

Keywords: Aluminium 6061, temperature aging, hardness, tensile strength, impact

\section{PENDAHULUAN}

Aluminium merupakan jenis material logam yang memiliki sifat ketahanan terhadap korosif yang baik dan sifat-sifat baik lainya sebagai sifat logam dengan density $2.70 \mathrm{~g} / \mathrm{cm}^{3}$ dan modulus elastisitas $10 \times 10^{6}$ psi (Surdia \& Saito, 1999)(Askeland \& Fulay, 2009). Karena sifatnya yang baik, Aluminium banyak digunakan di gunakan oleh industri pesawat, otomotif dan konstruksi karena sifatnya yang ringan dan kuat (Gunawan, 2017).

Salah satu jenis aluminum paduan yang banyak digunakan dalam dunia industri, yaitu Aluminium paduan seri 6061. Alumunium 6061 banyak digunakan untuk membuat beberapa part kendaraan bermotor dalam industri otomotif (Demir \& Gündüz, 2009). Komposisi paduan utama dalam alumunium 6061 yaitu magnesium $(\mathrm{Mg})$ dan silica ( $\mathrm{Si}$ ) (Randhiko, dkk,

\footnotetext{
${ }^{1}$ Jurusan Teknik Mesin, Fakultas Teknik Universitas Wahidiyah, Kediri, Indonesia

${ }^{2}$ Mahasiswa Jurusan Teknik Mesin, Fakultas Teknik Universitas Wahidiyah, Kediri, Indonesia

${ }^{3}$ Fakultas Teknik Universitas Negeri Jakarta, Jakarta, Indonesia

*Corresponding author:

e-mail: jaelani_s@uniwa.ac.id
} 
2018). Karena penggunaannya di berbagai industri yang memiliki karateristik kekuatan berbeda, diperlukan sebuah proses untuk meningkatkan kekuatan mekanik alumunium Paduan. Proses perlakuan panas (heat treatment) merupakan metode yang dapat digunakan untuk meningkatkan kekuatan Aluminium paduan (Pranata, dkk, 2014).

Artificial aging merupakan metode heat treatment untuk meningkatkan kekuatan alumunium. Hasil penelitian yang dilakukan oleh Rezaei, et.al (2011) menunjukan bahwa perlakuan panas artificial aging dapat meningkatkan nilai kekerasan dan kekuatan Tarik. Peningkatan sifat mekanik memungkinkan terjadi karena adanya pembentukan pertisipat pada matriks Aluminium, dalam hal ini yaitu endapan $\mathrm{Mg}_{2}$ dan Si yang mampu menghambat pergerakan dislokasi (Junus, et al., 2014)(Almansour, et al., 2015). Dengan demikian, memberikan perlakuan artificial aging terhadap material dengan pemilihan waktu yang tepat dapat meningkatkan nilai kekuatan mekanik yang optimum (Pranata et al., 2014).

Penelitian ini bertujuan untuk mengetahui perubahan sifat mekanik alumunium 6061 akibat perlakuan artificial aging. Variasi temperature aging betujuan untuk mencari temperatur yang optimum dalam meningkatkan sifat mekanik Aluminum 6061.

\section{METODOLOGI}

Penelitian ini dilaksanakan di Laboratorium Material Politeknik Kediri. Dalam penelitian ini digunakan bahan material Aluminium paduan seri 6061. Sebelum dilakukan pengujian, bahan penelitian dibuat spesimen untuk setiap pengujian, pengujian tarik dan pengujian kekerasan. Spesimen uji tarik dibuat dengan mengikuti standar ASTM D638, sedangkan untuk spesimen uji Kekerasan dibuat spesimen dengan dimensi 20x20x10 mm. untuk pengujian Impak, spesiemen dibuat menurut standar ASTM E23. Spesimen diberikan perlakuan perlakuan panas aging dengan variasi tempeartur $175^{\circ} \mathrm{C}, 200^{\circ} \mathrm{C}$ dan $225^{\circ} \mathrm{C}$ dengan waktu tahan pemanasan 1 jam kemudian didinginkan diudara terbuka. Adapun tahapantahapan yang dilakukan dalam penelitian ini tersusun secara sistematik dengan diagram alir yang ditunjukan pada Gambar 1. 


\section{Alat Penelitian}

Adapun alat-alat yang digunakan dalam penelitian ini sebgai berikut:

1. Tungku Pemanas

2. Mesin uji Tarik (WDW-20E)

3. Mesin uji kekerasan Rockwell Hardness Tester (Time Group)

4. Mesin uji impak Universal Impack Tester (Hung Ta Instrumen)

5. Pemotong logam

\section{HASIL DAN PEMBAHASAN}

\section{Hasil Uji Kekerasan}

Metode Rockwell digunakan dalam pengujian kekerasan dalam penelitian ini dengan beban uji 588.4 N. Pada pengujian kekerasan, masing-masing sample uji dilakukan pengujian sebanyak 3 titik. Kemudian dari tiga titik pengujian dihitung guna mendapatkan nilai rata-rata dan ditulis dengan skala Hardness Rockwell B (HRB). Tabel 1 menunjukan terjadi peningkatan nilai kekerasan pada Aluminium 6061 akibat perlakuan panas aging. Dimana Peningkatan maksimum terjadi pada temperatur $175^{\circ} \mathrm{C}$ dengan nilai rata-rata 31.66 (HRB). Penurunan nilai kekerasan terjadi seiring meningkatnya temperatur aging. Penurunan nilai kekerasan diakibatkan karena pada suhu $200^{\circ} \mathrm{C}$ dan $225^{\circ} \mathrm{C}$ sudah memasuki kondisi over aging.

Pada Gambar 2 menunjukan perlakuan panas aging dapat mempengaruhi nilai kekerasan Aluminium 6061. Peningkatan tersebut diakibatkan terjadinya proses precipitation hardening spesimen dan tertahannya pergerakan dislokasi saat terjadinya deformasi yang disebabkan dengan terbentuknya partikel pertisipat hasil proses aging (Smith, 1995) (Alhamidi, dkk, 2016). Membentuknya partikel pertisipat hasil proses aging berperan dalam meningkatkan nilai kekerasan Aluminium 6061 dengan menghambat pergerakan dislokasi. Peningkatan nilai kekerasan maksimum terjadi pada suhu $175^{\circ} \mathrm{C}$ dengan nilai $\mathrm{HRB}$ 31.66. Menurut (Zulfia, et al., 2013) kekerasan maksimum terjadi dikarenakan partikel pertisipat yang terbentuk akibat proses aging cukup besar dan rapatnya jarak antara partikel tersebut, sehingga pergerakan dislokasi dapat terhambat dengan maksimum. 


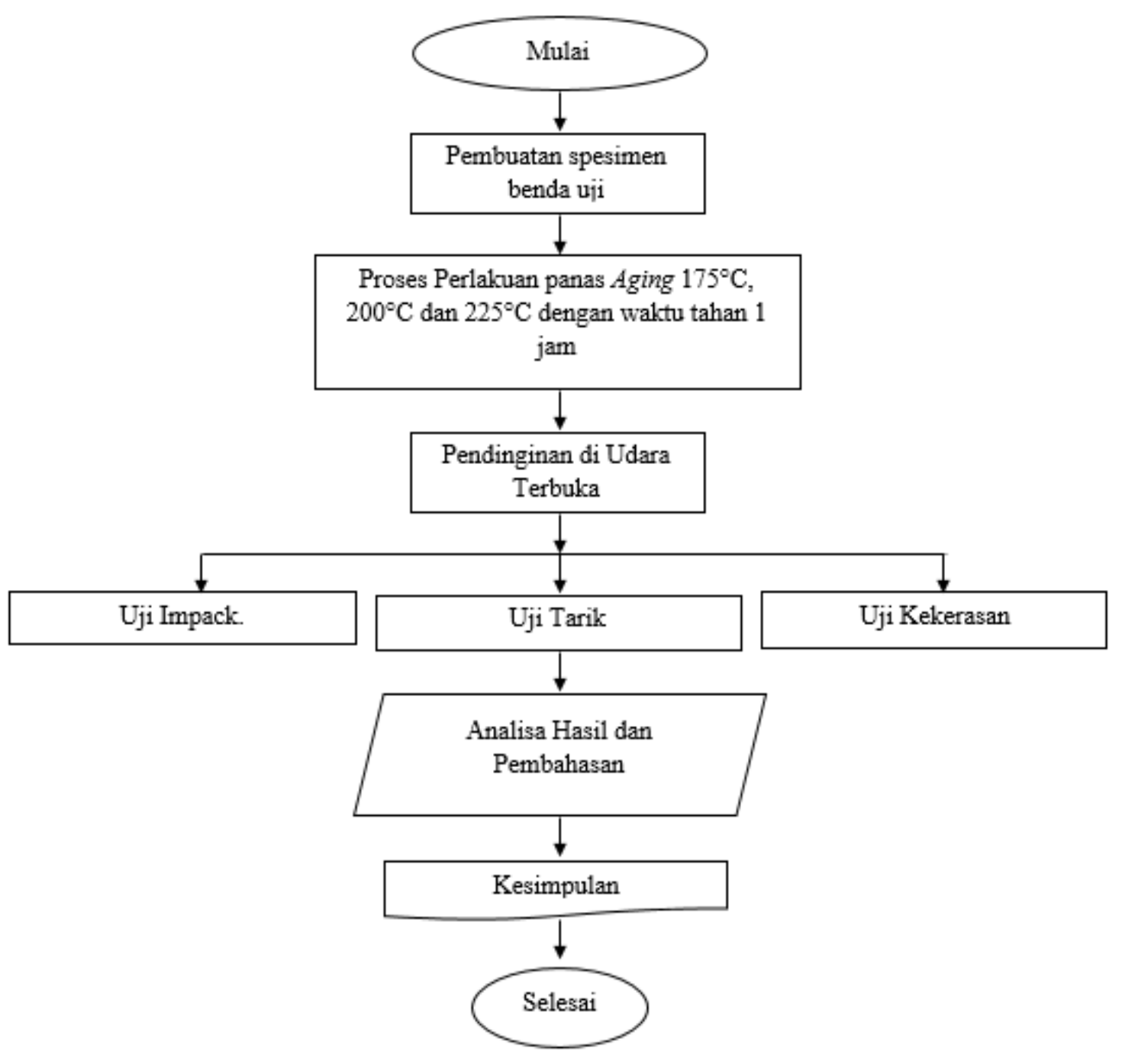

Gambar 1 Diagram Alir Penelitian

Tabel 1 Data Hasil Uji Kekerasan

\begin{tabular}{|c|c|c|c|c|}
\hline \multirow{2}{*}{ Pengujian } & \multicolumn{4}{|c|}{ Nilai Uji Kekerasan Rockwel (HRB) } \\
\cline { 2 - 5 } & \multicolumn{4}{|c|}{ Variasi Temperatur Aging $\left({ }^{\circ} \mathrm{C}\right)$} \\
\cline { 2 - 5 } & 0 & 175 & 200 & 225 \\
\hline 1 & 27.67 & 29.83 & 30.37 & 27.80 \\
\hline 2 & 26.50 & 35.17 & 28.57 & 26.07 \\
\hline 3 & 26.77 & 29.97 & 29.23 & 28.07 \\
\hline Rata-Rata & $\mathbf{2 6 . 9 8}$ & $\mathbf{3 1 . 6 6}$ & $\mathbf{2 9 . 3 9}$ & $\mathbf{2 7 . 3 1}$ \\
\hline
\end{tabular}




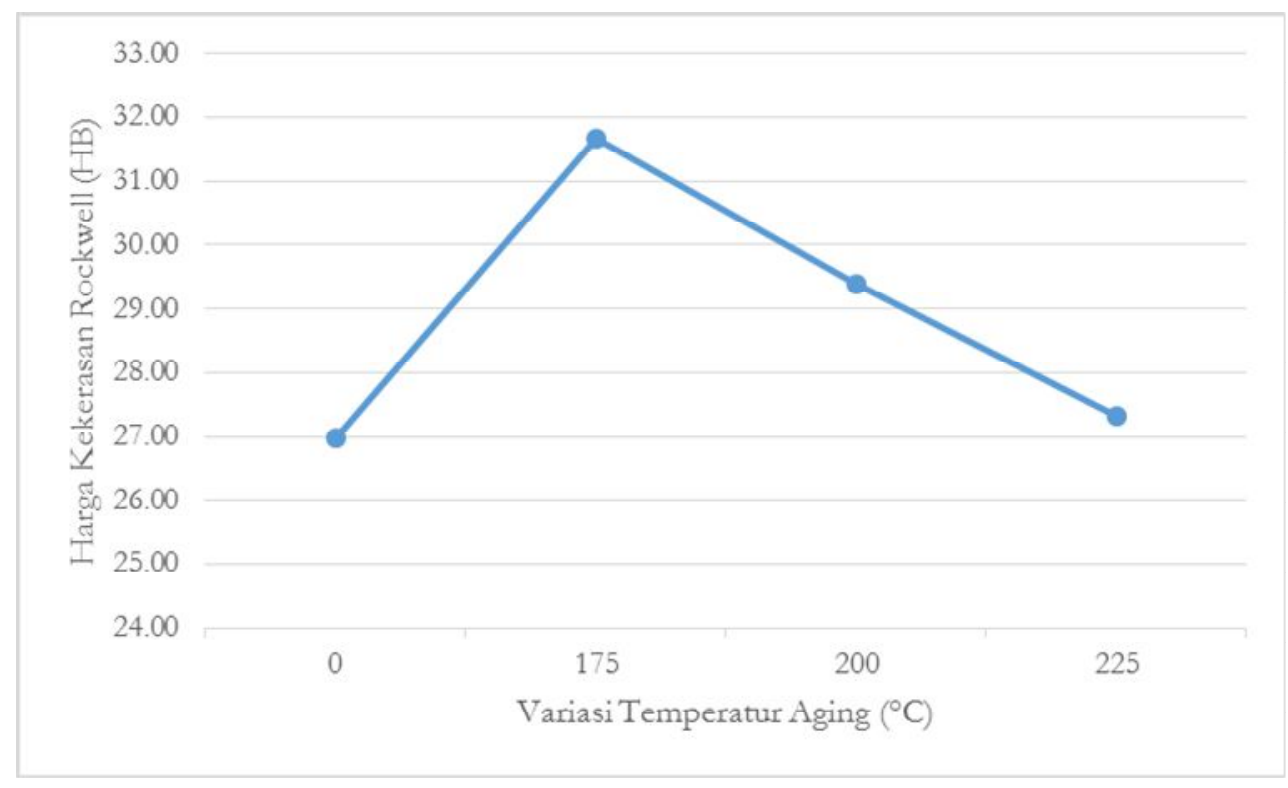

Gambar 2 Hubungan Temperatur Aging dan Hardness Rockwell B

Terjadi kondisi over aging pada suhu $200^{\circ} \mathrm{C}$ dan $225^{\circ} \mathrm{C}$ yang mengakibatkan nilai kekerasan menurun. Kondisi ini disebabkan karena pertisipat kembali pada fasa setimbang yang diakibatkan dengan meningkatnya temperatur aging (Mazda, 2016). Namun nilai kekerasan pada kondisi over aging masih lebih baik dibandingkan dengan nilai kekerasan tanpa perlakuan panas aging.

\section{Hasil Uji Tarik}

Berdasarkan hasil pengujian tarik, perlakuan panas aging berpengaruh terhadap peningkatan nilai kekuatan tarik Aluminium 6061. Secara umum, nilai kekuatan tarik meningkat dari kondisi awal atau tanpa perlakuan panas aging.

Berdasarkan Gambar 3, nilai kekuatan tarik maksimum terjadi pada temperatur aging $175^{\circ} \mathrm{C}$ dengan nilai kekuatan tarik (UTS) $231.67 \mathrm{Mpa}$. Temperatur aging sangat berpengaruh terhadap nilai kekuatan tarik Aluminium 6061 . Pada suhu $200^{\circ} \mathrm{C}$ dan $225^{\circ} \mathrm{C}$ nilai kekuatan tarik menurun dibandingkan pada suhu $175^{\circ} \mathrm{C}$ dengan nilai kekuatan tarik masing-masing 217.33 dan 206.67 Mpa. Dengan demikian, semakin meningkatnya temperatur aging, mengakibatkan terjadinya penurunan nilai kekuatan tarik pada Aluminium 6061. Namun, jika dibandingkan dengan Aluminium 6061 tanpa perlakuan panas aging nilai kekuatan tarik pada temperatur aging $200^{\circ} \mathrm{C}$ dan $225^{\circ} \mathrm{C}$ masih lebih tinggi. 


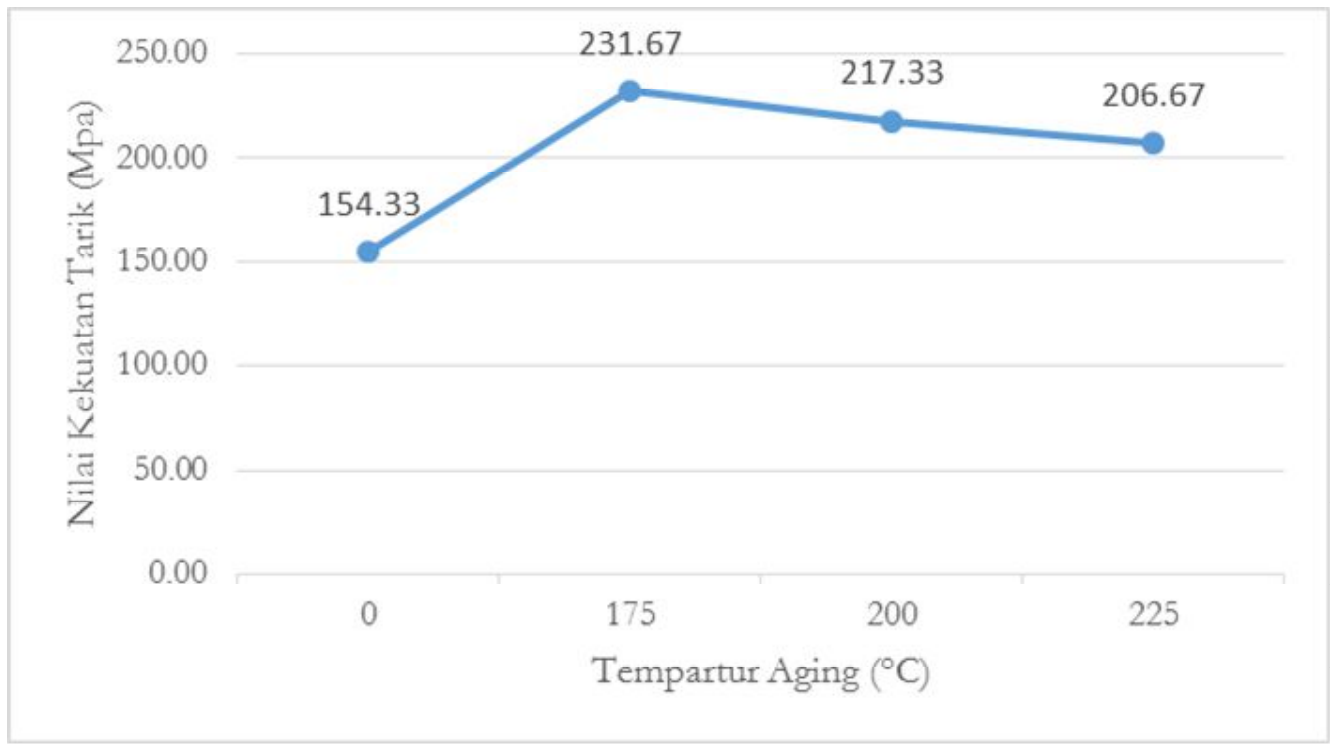

Gambar 3 Hubungan Temperatur Aging dan Nilai Kekuatan Tarik

\section{Hasil UJi Impak}

Tabel 2 menunjukan peningkatan usaha yang dibutuhkan untuk mematahkan benda uji dengan perlakuan panas aging semakin meningkat dibandingkan tanpa perlakuan panas aging. Usaha terbesar untuk mematahkan benda uji terjadi pada temperatur 175 dengan usaha 5.6607 Kg.m. semakin besar usaha yang dibutuhkan untuk mematahkan benda uji, semakin besar harga impak yang dihasilkan. Hasil pengujian impak ditunjukan pada Gambar 4.

Tabel 2. Usaha Yang diperlukan Untuk Mematahkan Benda Uji

\begin{tabular}{|c|c|c|c|c|}
\hline \multirow{2}{*}{ Pengujian } & \multicolumn{4}{|c|}{ Usaha Yang Diperlukan Mematahkan Benda Uji ( Kg m) } \\
\cline { 2 - 5 } & \multicolumn{4}{|c|}{ Variasi Temperatur Aging $\left({ }^{\circ} \mathrm{C}\right)$} \\
\cline { 2 - 5 } & 0 & 175 & 200 & 225 \\
\hline 1 & 1.250201 & 5.5193 & 5.1738 & 3.2667 \\
\hline 2 & 1.542439 & 5.6896 & 3.9178 & 2.9838 \\
\hline 3 & 1.054887 & 5.7740 & 4.9987 & 3.7332 \\
\hline Rata-Rata & 1.283368 & $\mathbf{5 . 6 6 0 7}$ & $\mathbf{4 . 7 0 2 9}$ & $\mathbf{3 . 3 2 8 7}$ \\
\hline
\end{tabular}

Berdasarkan Gambar 4, spesimen tanpa perlakuan panas aging memiliki harga impak sebesar $0.006581 \mathrm{Kg} . \mathrm{m} / \mathrm{mm}^{2}$. Harga impak meningkat sangat drastis pada spesimen dengan perlakuan panas aging pada temperature 175 dengan harga impak sebesar $0.0290 \mathrm{Kg} . \mathrm{m} / \mathrm{mm}^{2}$. Penignkatan terjadi selaras dengan meningkatnya kekuatan Aluminium 6061. Terjadi penurunan harga impak dengan semakin meningkatkan temperature aging, dimana pada suhu 
200 harga impak menurun dengan harga impak $0.0241 \mathrm{Kg} . \mathrm{m} / \mathrm{mm}^{2}$ dan pada suhu 225 harga impak $0.0171 \mathrm{Kg} \cdot \mathrm{m} / \mathrm{mm}^{2}$.

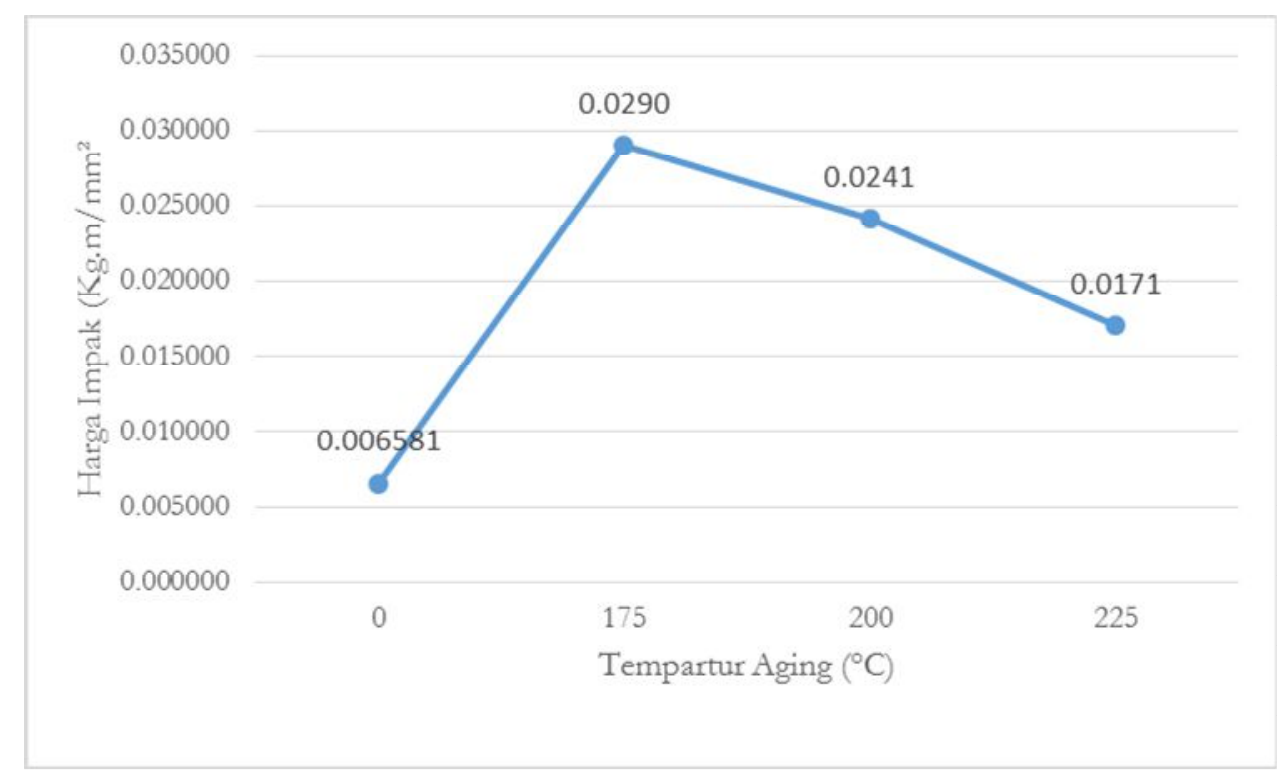

Gambar 4 Hubungan Temperatur Aging dengan Harga Impak

\section{KESIMPULAN}

Hasil penelitian menunjukan terjadi peningkatan sifat mekanik Aluminium 6061 akibat perlakuan panas aging. Hasil pengujian kekerasan, uji tarik dan uji impak mencapai peningkatan optimum pada suhu $175^{\circ} \mathrm{C}$ dengan nilai masing-masing $31.66 \mathrm{HRB}, 231.66 \mathrm{Mpa}$ dan $0.0290 \mathrm{Kg} \cdot \mathrm{m} / \mathrm{mm}^{2}$. Meningkatnya temperatur aging menyebabkan terjadinya penurunan sifat mekanik (kekerasan, kekuatan tarik dan harga impak) karena pada temperature tersebut sudah mencapai kondisi over aging, dalam penelitian ini kondisi over aging berada pada suhu $200^{\circ} \mathrm{C}$ dan $225^{\circ} \mathrm{C}$. Namun, nilai sifat mekanik tersebut masih tinggi dibandingkan dengan Aluminium tanpa perlakuan panas aging.

\section{DAFTAR PUSTAKA}

Alhamidi, A. L. I., Fitrullah, M., \& Dewi, M. (2016). Evolusi Mikrostruktur Paduan Al 6061 Hasil Proses Canai Dingin Terhadap Sifat Mekanik, 12(1), 25-34.

Almansour, A., Azizi, M., Jesri, A. M., \& Entakly, S. (2015). Effect of artificial aging on Structure, Mechanical properties and Corrosion behavior of Aluminum Alloy 6061. IJASR International Journal of Academic Scientific Research, 3(1), 24-33. Retrieved from http://www.ijasrjournal.org/wp-content/uploads/2015/03/MS3-15.pdf

Askeland, D. R., \& Fulay, P. P. (2009). Essentials of Materials Science and Engineering (2nd 
ed.). Toronto: Cengage Learning.

Demir, H., \& Gündüz, S. (2009). The effects of aging on machinability of 6061 Aluminium alloy. Materials and Design, $30 \quad$ (5), 1480-1483. https://doi.org/10.1016/j.matdes.2008.08.007

Pranata D.E.M., Alfirano, \& Jajat, M. (2014). Analisis Struktur Mikro Dan Sifat Mekanik Paduan Al 2014 Hasil Proses Aging dengan Variasi Temperatur dan Waktu Tahan.

Gunawan, S. (2017). Efek Perlakuan Panas Aging Terhadap Kekerasan Dan Ketangguhan Impak Paduan Aluminium Aa 514.0. T R a K Si, 16(1), 42-50.

Junus, S., Zulfia, A., Melisa, \& Mariani, L. (2014). Pengaruh Waktu Aging Terhadap Kekerasan dan Struktur Mikro Komposit Al-Si-Mg / Al 2 O 3 Dengan Metode Stir Casting. Jurnal ROTOR, 7(2), 6-9.

Mazda, B. T. (2016). Studi Eksperimental Pengaruh Variasi Holding Time dan Temperatur Aging Pada Perlakuan Panas Precipitation Hardening T6 Terhadap Sifat Mekanik Paduan Aluminium ADC 12.

Randhiko, A., Haryadi, G. D., \& Umardani, Y. (2018). Pengaruh Post Weld Heat Teatment (PWHT) T6 Pada Aluminium Alloy 6061-O dan Pengelasan Longitudinal Tungsten Inert Gas Terhadap Sifat Mekanik dan Struktur Mikro. Jurnal Teknik Mesin, 2(3), 167174. Retrieved from https://ejournal3.undip.ac.id/index.php/jtm/article/view/9608/9331 Rezaei, M. R., Toroghinejad, M. R., \& Ashrafizadeh, F. (2011). Journal of Materials Processing Technology Effects of ARB and ageing processes on mechanical properties and microstructure of 6061 aluminum alloy. Journal of Materials Processing Tech., 211(6), 1184-1190. https://doi.org/10.1016/j.jmatprotec.2011.01.023

Surdia, T., \& Saito, S. (1999). Pengetahuan Bahan Teknik (Vol. 4).

Zulfia, A., Juwita, R., Uliana, A., Jujur, I. N., \& Raharjo, J. (2013). Proses Penuaan (Aging) pada Paduan Aluminium AA 333 Hasil Proses Sand Casting. Jurnal Teknik Mesin, 12(1), 13-20. https://doi.org/10.9744/jtm.12.1.13-20 